\title{
Histopathological and Immunohistochemical Study of Antidiabetic Effects of Heracleum persicum Extract in Experimentally Diabetic Rats
}

\author{
Turan Yaman" ${ }^{* 1}$, Ahmet Uyar, Ismail Celik², Elif Ebru Alkan², Omer Faruk Keles', Zabit Yener ${ }^{1}$ \\ ${ }^{1}$ Department of Pathology, Faculty of Veterinary Medicine, Yuzuncu Yil University, Van, TURKEY. \\ ${ }^{2}$ Department of Molecular Biology and Genetics, Faculty of Bioscience, Yuzuncu Yil University, Van, TURKEY.
}

\begin{abstract}
Objective: This study aims to investigate the antioxidant properties and protective effects of Heracleum persicum (HP) extract in streptozotocin (STZ)-induced diabetic rats. Material and Methods: Forty-two Wistar albino male rats were divided into six groups including Control (C); Diabetes mellitus (DM); DM + Akarboz $20 \mathrm{mg} / \mathrm{kg} ; \mathrm{DM}+100 \mathrm{mg} / \mathrm{kg}$ HP extract (HP1); DM $+200 \mathrm{mg} / \mathrm{kg} \mathrm{HP}$ extract (HP2) and DM $+400 \mathrm{mg} / \mathrm{kg} \mathrm{HP}$ extract (HP3). Experimental diabetes was established by a single-dose $[45 \mathrm{mg} / \mathrm{kg}$, intra-peritoneal (i.p)] STZ injection. Essential dosages of HP extracts and Akarboz were applied with gastric gavage for 21 day. Results: In histopathological evaluation of the stained liver and kidney sections of diabetic rats showed degeneration and necrosis of hepatocytes, inflammatory cell infiltration and hydropic degeneration and necrosis in tubulus epithelial cells, disorder of glomerular structure and lymphocyte infiltration. These histopathological changes were ameliorated in the HP-treated rats depending on the dose level. Glutathione peroxidase 1 (GPx-1) immunoreactivity was detected in hepatocytes of liver and tubule epithelial cells of kidney. We have shown that treatment with extracts of HP modulates GPx-1 expression in HP-treated rats. STZ-induced degenerative changes in beta-cells caused decreases in the number of functioning beta-cells and insulin immunoreactivity in the pancreas of the diabetic rats. The pancreas of HP-treated rats were improved and the number of immunoreactive $\beta$ cells were significantly increased. Conclusion: Our data suggests that the STZ-induced immunohistochemical and histopathological alterations could be prevented by HP extract probably due to possess the ability to regenerate $\beta$-cells.
\end{abstract}

Key words: Heracleum persicum, Histopathology, Immunohistochemistry, Diabetes, Rat.

\section{INTRODUCTION}

Diabetes mellitus (DM) is a rapidly growing disease with a high mortality and morbidity risk. ${ }^{1} \mathrm{DM}$ is a chronic metabolic disorder characterized with hyperglycemia, which is formed as a result of insulin secretion, activation or defect in both. ${ }^{2}$ Chronic hyperglycemia in the course of DM contributes to the oxidative stress, causing the redox balance of the body to change with excessive production of reactive oxygen species. $^{3}$ Oxidative stress leads to an increase in protein, lipid, carbohydrate and DNA oxidation. Accordingly, it causes tissue and organ damage 4 . It is emphasized that this condition causes micro- and macrovascular complications of DM. ${ }^{5}$

Oxidative stress is observed to be increased in the liver, due to $\mathrm{DM}^{6}$. Since the liver has a central and critical role in the regulation of carbohydrate metabolism, ${ }^{7}$ various disorders affecting glycogen and lipid metabolism are formed in the liver as a result of DM. ${ }^{8}$ Similarly, the oxidative stress is effective in the pathogenesis of diabetic kidney complications. ${ }^{9}$ In addition, damage of $\beta$ cells of pancreas, which is known to
DOI: 10.5530/ijper.51.3s.66 Correspondence: Turan YAMAN, Department of Pathology, Faculty of Veterinary Medicine, Yuzuncu Yil University, 65080 Van, TURKEY.

Phone no: +90 4322251128 Email Id : turanyaman@yyu. edu.tr

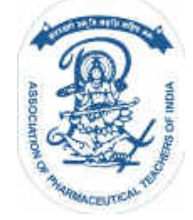

www.ijper.org 
be one of the most susceptible structures to oxidative stress, is thought to be caused due to toxic effects of hyperglycemia. ${ }^{10}$ Glycation-mediated free radical production leads to beta cell apoptosis and decreases the gene transcription of insulin. ${ }^{11}$

Glutathione peroxidase (GPx) is one of the natural antioxidant defense system against free radicals It protects lipid peroxidation by catalyzing the reduction of hydrogen peroxide $\left(\mathrm{H}_{2} \mathrm{O}_{2}\right),{ }^{12}$ and it protects cell membranes against oxidative injury. ${ }^{13}$ GPx-1 is is an intracellular selenoprotein with high expression levels in erythrocytes, liver, and kidneys. ${ }^{14,15}$

Heracleum persicum (HP) has been known as "Suh" in Turkey. In consequence of atherosclerosis antioxidant capacities of HP Desf, species of Apiaceae family were assessed by identifying their effects on radical scavenging and lipid peroxidation inhibition as well as their total phenolic contents. ${ }^{16,17}$ Pimpinellin, bergapten, isopimpinellin, sphondin and isobergapten are furanocoumarins which are reported from roots of this plant. HP fruits are a rich source of furanocoumunaris which might act as an immunostimulatory agent. ${ }^{18} \mathrm{HP}$ has stimulated both humoral as well as cellular arms of the immune system. Major constituents of HP essential oil were reported as Hexyl butyrate ( $\%$ 56,5), octyl acetate $(\% 16,5)$, hexyl 2-methylbutanoate $(\% 5,2)$ and hexyl isobutyrate $(\% 3,4){ }^{19}$

In this study, we aimed to present the protective effects of HP extract on the liver, kidney and pancreas against the experimental diabetic complications in rats histopathologically and immunohistochemically.

\section{MATERIALS AND METHODS}

\section{Plant material extract}

Plant samples were collected from Turkey (Hizan/Bitlis) in August 2015. The identity of the plant materials was confirmed by Fevzi Ozgokce, $\mathrm{PhD}$, at the Biological Sciences Department, Science Faculty, Yuzuncu Yil University, Turkey, and a voucher specimen stored at the university's herbarium (Heacleum persicum DESF. herbaryum No:165061). The plant materials were promptly washed with distilled water and were left at room temperature in the dark until dry. Subsequently, the samples were ground and stored at $20 \mathrm{C}$ until analyzed. The lyophilized extract was prepared as described previously ${ }^{20}$ with some modifications.

\section{Animals}

Forty-two Wistar albino male rats 3-4 months of age, weighing 200-300 g, were provided by the animal house of the Medical School of Yuzuncu Yil University.
Animals were housed at $20 \pm 2{ }^{\circ} \mathrm{C}$ in daily light/dark cycle. All animals were kept in stainless cages and fed with wheat-soybean-meal-based diet. Water and feed were offered ad libitum. The ethic regulations have been followed in accordance with The National and Institutional guidelines for the protection of animal welfare during experiments. This study was approved by The Ethic Committee of the Yuzuncu Yil University (02.01.2014/01).

\section{Induction of diabetes}

The animals were fasted for $12 \mathrm{~h}$ prior to the induction of diabetes. Streptozotocin (STZ) freshly prepared in citrate buffer $(0.1 \mathrm{M}, \mathrm{pH} 4.5)$ was administered intraperitoneally (i.p.) at a single dose of $45 \mathrm{mg} / \mathrm{kg}$. Seventy-two hours after, blood glucose levels of STZ-treated fasted rats greater than $200 \mathrm{mg} / \mathrm{dl}$ were considered as diabetic and used in this study.

\section{Experimental model}

The rats were randomly divided into six groups each containing seven (n $1 / 4$ ) rats.

Normal control group (NC): NC rats received citrate buffer (pH 4.5) (1 ml/kg, i.p.).

Diabetes mellitus group (DM): DM rats received STZ in a single dose (45 mg/kg, i.p.).

Diabetes mellitus + Acarbose (DM + AC-20) $(20 \mathrm{mg} / \mathrm{kg}$ b.w.) group: Acarbose $(20 \mathrm{mg} / \mathrm{kg}$, per day) was treated to diabetic rats via orally during $21 \mathrm{~d}$.

Diabetes mellitus + Extract (DM + Extract-100) $(100$ $\mathrm{mg} / \mathrm{kg}$ b.w.) group: HP lyophilized extract $(100 \mathrm{mg} / \mathrm{kg}$, per day) was treated to diabetic rats via orally during $21 \mathrm{~d}$. Diabetes mellitus + Extract (DM + Extract-200) (200 $\mathrm{mg} / \mathrm{kg}$ b.w.) group: HP lyophilized extract $(200 \mathrm{mg} / \mathrm{kg}$, per day) was treated to diabetic rats via orally during $21 \mathrm{~d}$. Diabetes mellitus + Extract (DM + Extract-400) (400 $\mathrm{mg} / \mathrm{kg}$ b.w.) group: HP lyophilized extract $(400 \mathrm{mg} / \mathrm{kg}$, per day) was treated to diabetic rats via orally during $21 \mathrm{~d}$.

\section{Histopathological examination}

At the end of experiments, the rats were anesthetized by injection of ketamine ( $5 \mathrm{mg} / 100 \mathrm{~g}$ body weight) i.p. Tissue samples were taken from the testicles and fixated in Boin's solution. After routine tissue follow-up, the samples were embedded into paraffin blocks; $4 \mu \mathrm{m}$-sections were taken using microtome (Leica RM 2135); stained with hematoxylin-eosin and examined under light microscope (Nikon 80i-DS-RI2). Histopathological findings were graded in three ways; slight $(*)$, medium $(* *)$, and severe $(* * *)$. 


\section{Immunohistochemistry (IHC) staining}

Immunohistochemistry was performed to investigate GPx1 and insulin expressions. The streptavidinperoxidase method $(A B C)$ was used to stain the sections. Commercial antibodies were visualized on $5-\mu \mathrm{m}$-thick paraffin sections using an indirect streptavidin/biotin immunoperoxidase kit (Histostain Plus Bulk Kit, Zymed, South San Francisco, CA, USA). Tissue sections were incubated with the GPx1 (abcam-ab22604) (1:400) and insulin (abcam ab-181547) (1:1000) primary antibodys overnight at $4^{\circ} \mathrm{C}$. Finally, to visualize the reactions, the sections were reacted for 5-15 min with diaminobenzidine (DAB) for GPx1 and insulin staining.

\section{RESULTS}

\section{Histological findings}

\section{Liver}

The normal histological view of the liver was observed in the control group (Figure 1-A). Extensive hydropic degeneration in hepatocytes and necrosis as a single component were observed in liver sections of DM group rats. Large or small, irregularly-edged, partially rounded vacuoles were observed in the cytoplasm of degenerated hepatocytes. Mild fibrosis, bile duct proliferation, inflammatory cell infiltration were detected in portal areas. The normal arrangement of hepatocyte cords was observed to be impaired and became an irregular cell community (Figure 1-B). These findings were found to be significantly decreased in the liver of rats in $\mathrm{DM}+$ Acarbose treatment group as well as degeneration and necrosis was observed locally in hepatocytes (Figure 1C). Also, findings were found to be significantly reduced in HP1 and HP2 and HP3 (400 mg/kg) group rats treated with HP extract (Figure 1-D).

\section{Kidney}

The normal histological view of the kidney was observed in the control group (Figure 2-A). In DM group rats kidney, hydropic degeneration and necrosis were observed significantly in tubulus epithelial cells. Focal inflammatory cells were seen in the intertubular areas. Bowman capsule of glomerulus were observed to be enlarged whereas some parts of it was found to be narrowed. Glomeruli, which were narrowed in bowman capsule, were observed to create adhesion with the basal membrane (Figure 2-B). Mild hydropic degeneration and necrosis were observed in some parts of the tubular epithelial cells in the kidney of rats in DM + Acarbose treatment group. Additionally, adhesions were observed in bowman capsule of some glomerulus (Figure 2-C). The findings were detected to be significantly reduced in the kidney of rats in HP1 $(100 \mathrm{mg} / \mathrm{kg})$, HP2 (200 $\mathrm{mg} / \mathrm{kg}$ ) and HP3 (400 mg/kg) group rats (Figure 2-D).

\section{Pancreas}

The islets of Langerhans were observed to be large and regular as well as their limits were identified well. The islet cells of Langerhans were found to be in a normal histologic appearance (Figure 3-A). The most importent changes in the group with $\mathrm{DM}$ were degenerative and necrotic changes in the islet cells of Langerhans. Significant cell loss was observed in the islets as well as the cellular order was disrupted, the islets were atrophied and the structure was deteriorated. Hydropic degeneration and degranulation were observed in the cytoplasm of degenerative cells, and nucleus and cytoplasm were observed to be stained with a dark color (Figure 3-B). Degenerative and necrotic changes were formed in only several cells in DM + Acarbose treatment group (Figure 3-C). A significant improvement was observed in the islet of Langerhans of rats in HP1 $(100 \mathrm{mg} / \mathrm{kg}), \mathrm{HP} 2$ $(200 \mathrm{mg} / \mathrm{kg})$ and HP3 $(400 \mathrm{mg} / \mathrm{kg})$ treatment group rats (Figure 3-D).

\section{Imunohistochemical findings \\ Liver}

Control group had the most intense staining. GPx-1 immunoreactivity was observed to be formed in the same density in the centrilobular, midzonal and periasiner regions of the liver. GPx-1 immunoreactivity was found to be only cytoplasmic in some of hepatocytes, and observed to be more intense both cytoplasmic and nuclear. No staining was observed in Kupffer cells and sinusoidal vessel endothelium (Figure 4-A). In the DM group, GPx-1 immunoreactivity was detected less in both the nucleus and cytoplasm of the cells compared to the control group (Figure 4-B). Immunreactivity was observed more intense in $\mathrm{DM}+$ Acarbose treatment group rats than DM group whereas it was observed to be lower than control group (Figure 4-C). HP1 (100 $\mathrm{mg} / \mathrm{kg}$ ), HP2 (200 mg / kg) and HP3 (400 mg / kg) treatment groups had higher staining density than DM group (Figure 4-D).

GPx-1 immunoreactivity was observed in the kidney tissue sections which were received from all groups. Control group had the most intense staining. GPx-1 showed immunoreactivity in distal and proximal tubular epithelial cells, particularly in collecting tubules. No immunoreactive reaction was observed in the glomerulus and bowman capsules. GPx-1 immunoreactivity was found to be more intense both cytoplasmically and nuclearly; however, it was found less only cytoplasmically (Figure 5-A). The GPx-1 immunoreactivity was 


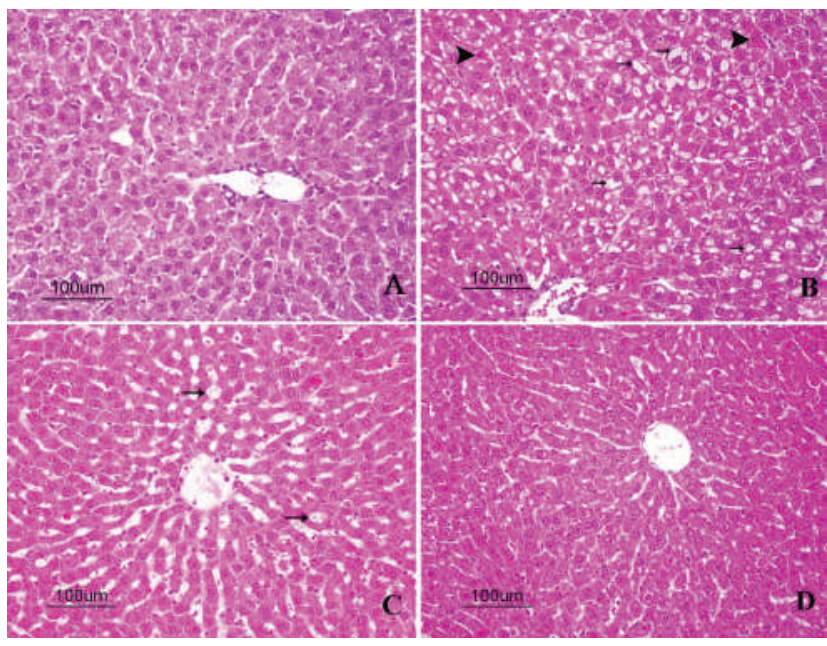

Figure 1 (A-D): Liver sections stained with hematoxylin and eosin. (A): Normal histological view of liver in control group rats. (B): Histologic appearance from the liver tissue of a rat belonged to diabetic group showing vacuolar hydropic degeneration (Arrow) and coagulative necrosis in hepatocytes (arrow heads). (C): Liver from an animal treated with acarbose showing dissociation in remarc cordons (arrow). (D): Liver from an animal treated with $400 \mathrm{mg} / \mathrm{kg}$ (DM+HP3 group) showing almost normal morphology.
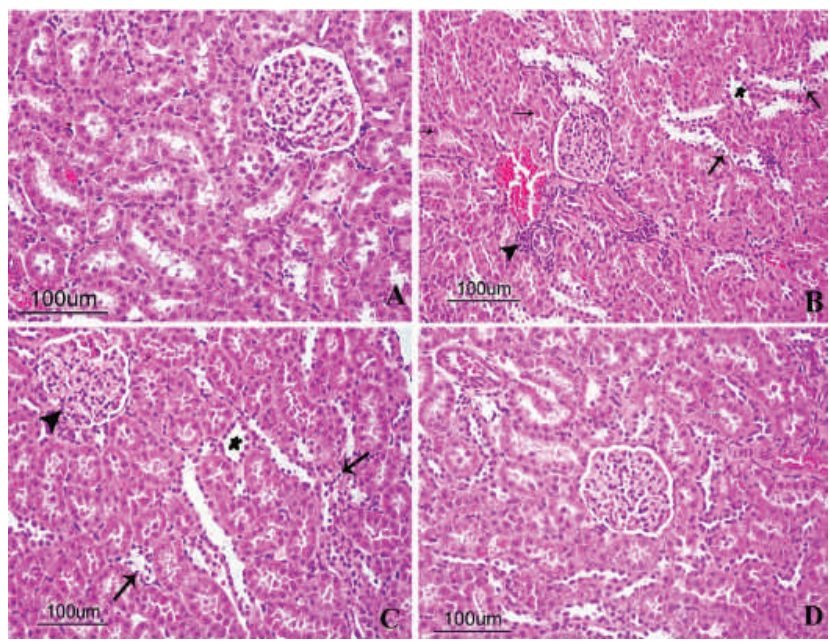

Figure 2 (A-D): Kidney sections stained with hematoxylin and eosin. (A): Normal histological view of kidney in control group rats. (B): Section of kindey from the DM group rats showing necrosis (thin arrows) and vacouler dejeneration (thick arrows) in tubular epithelium cells, inflammatory cell infiltration (arrowheads) and dilatation of tubulus (star) (C): Kidney section of a rats from DM+acarbose group showing hydropic dejeneration in tubular epithelium cells (arrows), dilatation of tubulus (star); and deterioration of the glomerular structur. (D): Kidney section of a rats from HP3 group $(400 \mathrm{mg} / \mathrm{kg}$ ) showing nearly histological view of kidney in control group.

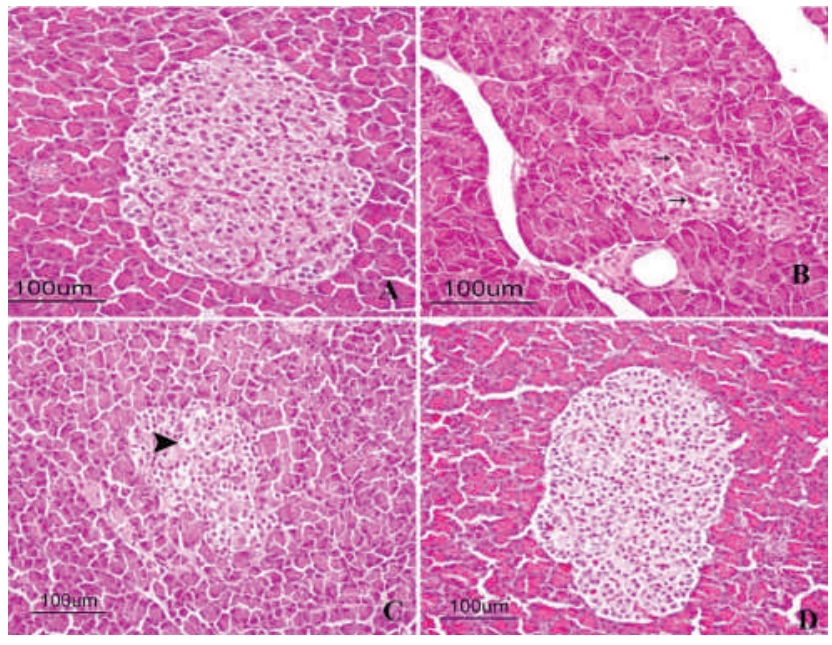

Figure 3 (A-D): Pancreas sections stained with hematoxylin and eosin (A): Normal histological view of pancreas in control group rats. (B): Pancreas section of a rat from DM group showing a shrunken and distorted islet of Langerhans displaying cells with vacuolated cytoplasm and large darkly stained nuclei (arrows). (C): Section of pancreas from acarbose treated group rats showing shrunken and distorted islets of Langerhans (arrows) contained cells with degenerative and necrotic changes (Arrowhead). (D): Pancreas section of a rat from HP3 group ( $400 \mathrm{mg} / \mathrm{kg}$ ) showing normal islet of langerhans with numerous $\beta$-cells.

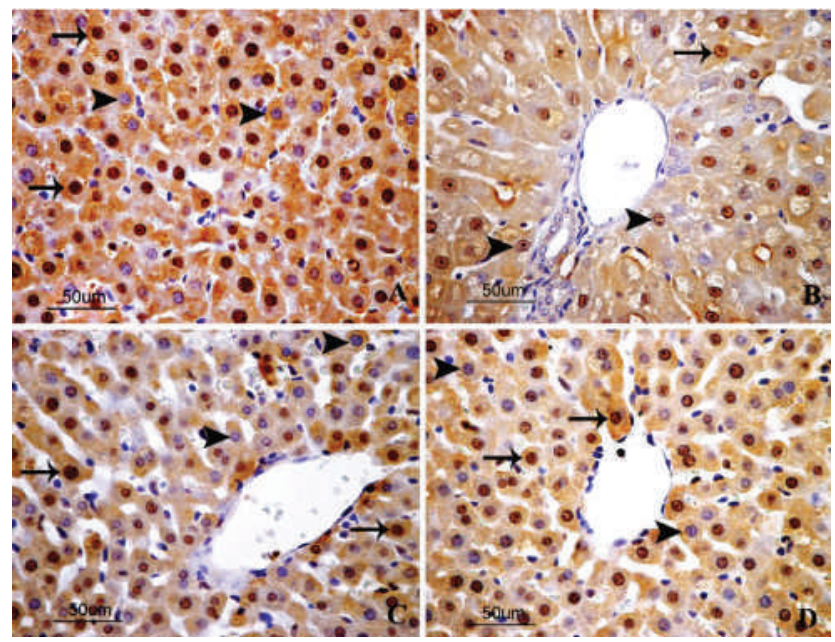

Figure 4 (A-D): Immunlocalization of GPx1 in liver tissue of rats. (A): Cytoplasmic and nuclear expression of GPx1 in liver section of control group rats. The localization of GPx1 was found in the hepatocytes in periacinar and midzonal areas. (B): Liver section of from DM group showing weak nuclear and cytoplasmic staining of GPx1 in comparison with control group. (C): Liver section of rat from DM + acarbose group showing intense cytoplasmic and nuclear GPx1 immunoreactivity in comparison with DM group. (D): Liver section of rat from HP3 group $(400 \mathrm{mg} / \mathrm{kg})$ showing strong cytoplasmic and nuclear GPx1 immunoreactivity in hepatocytes in comparison with DM group (D). Arrowhead = cytoplasmic GPx1 immunoreactivity, arrow $=$ cytoplasmic and nuclear GPx1 immunoreactivity. 


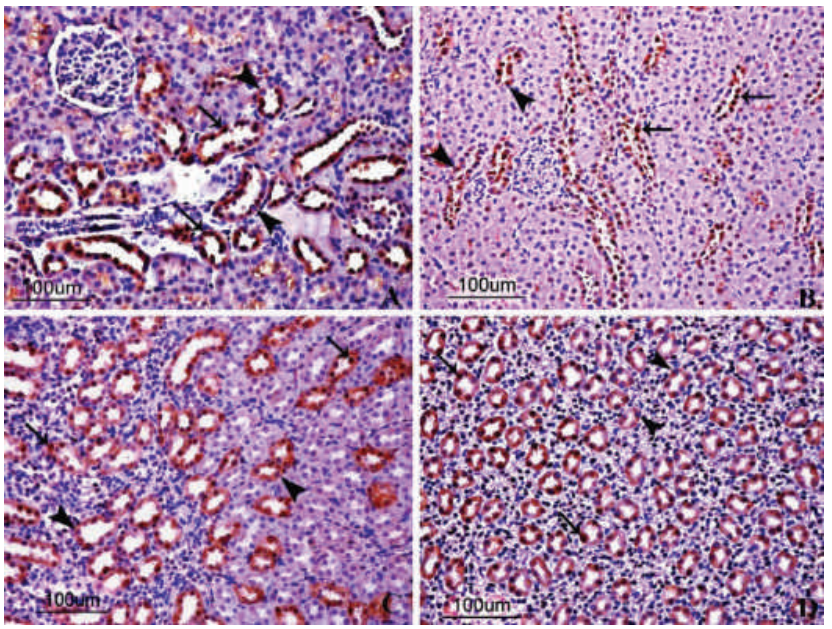

Figure 5 (A-D): Immunlocalization of GPx1 in kidney tissue of rats. (A) Cytoplasmic and nuclear expression of GPx1 in kidney section of control group rats. The localization of GPx1 was found predominantly in distal and proximal convoluted tubules and collecting ducts. (B) Kidney section of diabetic group showing slight cytoplasmic and nuclear expression of GPx1 in distal and proximal tubules. (C) Kidney section of DM + acarbose group rats showing intense cytoplasmic and nuclear GPx1 immunoreactivity in the distal and proximal tubules. (D) Kidney section of diabetic rats treated with $400 \mathrm{mg} / \mathrm{kg} \mathrm{HP}$ extract showing strong cytoplasmic and nuclear GPx1 immunoreactivity in collecting ducts. (D). Arrowhead ; cytoplasmic GPx1 immunoreactivity, arrow ; cytoplasmic and nuclear GPx1 immunoreactivity.

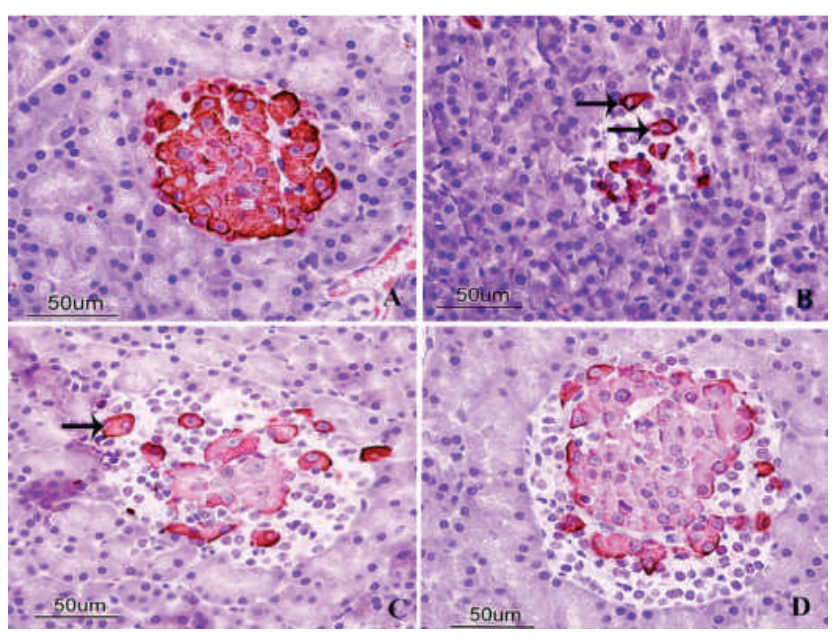

Figure $6(A-D)$ : Immunohistochemical staining of insulin in pancreatic islets of rats. (A) Pancreas section of rats from control group showing strong immunoreactivity of insulin in beta-cells, which occupy most of the islet. (B) Pancreas section of a rats from DM group showing evident decline in the immunohistochemical expression of insulin in beta-cells (arrows). (C) In the pancreas of DM+Acarbose group rats, the apparent marked increase in number and area of beta-cells

is evident in comparison with DM group (arrow). (D)

Pancreas section of rats from HP3 group $(400 \mathrm{mg} / \mathrm{kg})$ showing an evident increase in insulin expressing beta-cells with normal density, compared with DM group. found to be weaker and fewer in the DM group (Figure 5-B). However, GPx-1 immunoreactivity in the kidney sections of DM + Acarbose and HP treatment groups was less than in the control group, and it was found to be stronger in more cells compared to DM group (Figure 5-C,D).

Intense insulin immunopositive reaction areas were observed in pancreatic tissue sections and the islets of Langerhans of the control group rats (Figure 6-A). The insulin-positive areas in pancreases of rats in DM group were observed to be considerably reduced compared to the control group (Figure 6-B). Acarbose treatment group had more insulin-positive area than the DM group (Figure 6-C). HP1 (100 mg / kg) treatment group showed significant increase compared to DM group whereas the appearance of insulin immunopositive areas in pancreatic sections of HP2 $(200 \mathrm{mg} / \mathrm{kg})$ and HP3 (400 mg / kg) treatment groups was almost similar with the control group. This condition was recorded as the most significant result of this study (Figure 6-D).

\section{DISCUSSION}

Diabetes mellitus is one of the oxidative stress conditions in which free radicals are increased and/or antioxidant mechanisms are inhibited. ${ }^{5}$ Free radicals induce Oxidative stress and can lead to injury of cellular membrane. ${ }^{21,22}$ Free radical formation has been reported to be a direct consequence of hyperglycemia. ${ }^{23}$ Expression of antioxidant enzymes such as superoxide dismutase, glutathione peroxidase and catalase are known to be in the lowest level in pancreatic islet cells compared to other tissues such as the liver, kidney and adipose tissue. ${ }^{24}$ Increased free radicals may lead to degradation of cellular functions and oxidative damage to membranes by consuming antioxidant defense components. ${ }^{25}$ As a result, prolonged oxidative stress and changes in antioxidant capacity may be related to the occurrence of longterm complications of DM. ${ }^{26}$ Plants with antioxidant activity and some of the active ingredients obtained from these plants are thought to be useful in the treatment of DM since they provide protection against oxidative stress caused by hyperglycemia and have positive effects on glucose metabolism. ${ }^{27}$ Studies have revealed that these compounds have a sweeping effect on free radicals and have a strong antioxidant role. ${ }^{28,29}$

The liver has been reported to be a central metabolic organ and is exposed to reactive oxygen species due to oxidative damage resulting from DM. ${ }^{30}$ In STZ-induced diabetes studies, necrosis in hepatocytes, inflammatory cell infiltration, lipidosis, ${ }^{31}$ dilation in sinuses ${ }^{32}$ and impairment in portal intervals ${ }^{33}$ are reported histopathological 
findings. In this study, similar findings were observed in the DM group rats. These results were observed to be significantly reduced in HP1, HP2 and acarbose treatment groups; however, the liver of HP3 group rats was found to have a similar appearance with the liver of control group rats. These results indicated that HP extract may greatly ameliorated hepatocyte degeneration, necrosis and infiltration of inflammatory cells associated with development of DM.

Thickening in diabetic kidneys and glomerulus basal membranes, mesangial enlargement, hypertrophy, glomerular epithelial cell (podocyte) $\operatorname{loss}^{4}$ interstitial cell infiltration, tubular dilatation and atrophy are among the reported histopathological findings. ${ }^{34}$ In this study, degeneration and necrosis of the tubular epithelial cells in the DM group and deterioration of the glomerulus structures were at the forefront. The findings of the treatment groups were found to be decreased significantly; however, the similar appearance of the kidneys of rats in HP3 treatment group with the control group was reported as a significant result.

Reduction of GPx levels, which is among antioxidant enzymes, is thought to be occurred due to inactivation of antioxidant enzymes as a result of glycation caused by hyperglycemia in $\mathrm{DM}^{35}$. GPx depletion may have a major role in the pathogenesis of vascular complications and microalbuminuria with increased oxidative stress. ${ }^{36}$ In a study by Yoshimura et al. ${ }^{37}$ GPx was found to be localized diffusely in the cytoplasm of hepatocytes in the liver of rats. Additionally, periportal area had more intense staining than the centriobular area, and no staining was reported in endothelial cells around the sinusoids and in Kupffer cells. Asayama et al., ${ }^{38}$ observed staining in cytoplasm, nucleus, mitochondria and other cell organelles in a study on the intracellular distribution of cellular GPx in rat hepatocytes. Asayama et al. ${ }^{39}$ reported that GPx-1 was stained immunohistochemically at similar concentrations in centrilobular and periportal areas of hepatocytes in the liver of fetal and neonatal rats. In this study, GPx-1 immunoreactivity was found to be cytoplasmic in some hepatocytes, and cytoplasmic and nuclear in common. Staining in hepatocytes was similar in centrilobular, midzonal and periportal areas. GPx-1 immunoreactivity was not observed in the endothelial cells and connective tissue of the vessels in the Kupffer cells, central venous and portal vein similar to other studies. ${ }^{40}$ In addition to this, poor immunoreactivity was observed in some bile duct epithelial cells.

In this present study, all groups had similar GPx-1 immunolocalization in their livers, and GPx-1 immunoreactivity levels of DM group was found to be in a few cells and weaker compared to the control group in accordance with previous studies. ${ }^{40,41}$ Deprem et al. ${ }^{42}$ reported that capsaicin treatment decreased the GPx-1 immunoreactivity in the liver of diabetic rats whereas Taşç1 and Gülmez ${ }^{41}$ reported that melatonin treatment increased the GPx-1 immunoreactivity in the liver. In the present study, we found that GPx-1 immunoreactivity in the liver of rats treated with HP extract increased significantly compared to rats in the DM group.

In studies, GPx-1 immunoreactivity has been reported to be observed in glomerulus, cytoplasm of proximal and distal tubulus epithelia, transitional epithelium of kidney and smooth muscle cells of kidney arteries. ${ }^{43}$ GPx had a wide intracellular distribution with its localization in mitochondria, peroxisome, nucleus and cytoplasm in the kidney cells. ${ }^{43}$ In this study, cytoplasmic and nuclear staining were observed in some of the collecting duct epithelial cells, proximal and distal tubulus epithelia of the GPx-1 immunoreactivity whereas only cytoplasmic staining was observed in less cells. However, no staining was observed in glomerulus and bowman capsule. GPx-1 immunoreactivity was observed to be higher in control group, and less in DM group. HP1 and HP2 treatment groups had more intense staining than DM group whereas HP3 treatment group had an approximate GPx-1 immunoreactivity level with the control group.

In experimental studies, toxicity of STZ-induced pancreatic $\beta$-cells was investigated, and these cells were thought to be damaged due to production of reactive oxygen species. ${ }^{44}$ In this study, the morphology of the islets of Langerhans was observed to be deteriorated and become atrophic in the pancreases of DM group rats, and endocrine cells showed significant cytoplasmic vacuolization and picnotic nucleus formation as a result of STZ application. These histological findings were found to be consistent with the conducted studies. ${ }^{45,46}$ The changes was observed to be significantly decreased as a result of HP extract treatmen.

In recent studies, it has been suggested that regeneration of $\beta$-cells may be possible after they are damaged severely due to STZ therapy. ${ }^{47,48}$ Studies of STZ-induced diabetes have shown that the number of immunoreactive cells was decreased against the insulin antibodies in the pancreatic islets of rats. Pancreatic islets were found to be protected morphologically thanks to the treatment with plant extracts, and the immune response was reported to be enhanced for the insulin antibodies. ${ }^{49,50}$ Our results show that HP extracts at a dose of 100, 200 and $400 \mathrm{mg} / \mathrm{kg} \mathrm{BW} /$ day can induce significant amelioration in the functioning of beta-cells. These effects may be a consequence of the protection of $\beta$-cells from oxidative stress. 
In another study evaluating the biochemical results of this study ${ }^{51} \mathrm{HP}$ extract was reported to have biochemical anti-diabetic, anti-hyperglycemic and anti-oxidant effects on blood and tissues, and it has protective effects for tissues against the oxidative damage occurred in DM in terms of blood serum enzyme levels, antioxidant enzymes in tissues and lipid peroxidation (MDA) values. ${ }^{51}$ These biochemical results were consistent with the histopathological and immunohistochemical findings of our study.

\section{CONCLUSION}

In conclusion, HP extract has been shown to prevent damage, which is formed in liver, kidney and pancreas due to possible antioxidant activity, in the experimental diabetes model developed with STZ in accordance with the results of this study. Therefore, HP extract seems to be useful in the treatment of diabetic related complications.

\section{ABBREVIATION USED}

The authors thank to Dr. Suleyman Mesut PINAR who confirmed plant materials.

\section{CONFLICT OF INTEREST}

The authors declare no conflict of interest.

\section{ABBREVIATIONS}

DM: Diabetes mellitus; HP: Heracleum persicum; GPx: Glutathione peroxidase; STZ: Streptozotocin.

\section{REFERENCES}

1. Pitkanen OM, Martin JM, Hallman M, Akerblom HK, Sariola H, Andersson SM. Free radical activity during development of insulin dependent diabetes mellitus in the rat. Life Sci. 1992;50(5):335-9.

2. Huang THW, Peng G, Kota BP, Li GQ, Yamahara J, Roufogalis BD Li Y. Anti-diabetic action of Punica granatum flower extract: activation of PPAR-c and identification of an active component. Toxicol Appl Pharmacol. 2005;207(2):160-9.

3. Prasath GS, Subramanian SP. Fisetin, A tetra hydroxy flavone recuperates antioxidant status and protects hepatocellular ultrastructure from hyperglycemia mediated oxidative stress in streptozotocin induced experimental diabetes in rats. Food Chem Toxicol. 2013;59:249-55.

4. Yachamaneni J, Dhanraj S. Anti-Hepatotoxic and Antioxidant Activity of Limnanthemum indicum Against Carbon Tetrachloride Induced Liver Toxicity in Rats. IJPER. 2016; DOI: 10.5530/ijper.51.2.38.

5. Memisogulları M. Diyabette serbest radikallerin rolü ve antioksidanların etkisi. Duzce Med J. 2005;3:30-9.

6. Tolman KG, Fonseca V, Dalpiaz A, Tan MH. Spectrum of liver disease in type 2 diabetes and management of patients with diabetes and liver disease. Diabetes care. 2007;30(3):734-43.

7. Levinthal GN, Tavill AS. Liver disease and diabetes mellitus. Clin Diabetes. 1999;17(1):73-93.
8. Sanchez SS, Abregu AV, Aybar MJ, Sanchez Riera AN. Changes in liver gangliosides in streptozotocin-induced diabetic rats. Cell Biol Int. 2000;24(12):897-904.

9. Brownlee, M. Biochemistry and molecular cell biology of diabetic complications. Nature. 20014;14(6865),813-20.

10. Robertson RP, Harmon J, Tran PO, Poitout V. $\beta$-cell glucose toxicity, lipotoxicity, and chronic oxidative street inn type 2 diabetes. Diabetes. 2004;53(Suppl1):119-24

11. Donalth MY, Gross DJ, Cesari E, Kaiser N. Hyperglycemia- induced $\beta$ cell apoptosis in pancreatic islets of Psammoys obesus during development of diabetes. Diabetes. 1999;48(4):738-44.

12. Herbette $S$, Roeckel-Drevet $P$, Drevet JR. Seleno-independent glutathione peroxidases. More than simple antioxidant scavengers. FEBS J. 2007;274(9):2163-80.

13. Czuczejko J, Zachara BA, Staubach-Topczewska E, Halota W, Kedziora J. Selenium, glutathione and glutathione peroxidases in blood of patients with chronic liver diseases. Acta Biochim Pol. 2003;50(4):1147-54.

14. Lubos E, Loscalzo J, Handy DE. Glutathione peroxidase-1 in health and disease: from molecular mechanisms to therapeutic opportunities. Antioxid Redox Signal. 2011;15(7):1957-97.

15. Lipinski B. Pathophysiology of oxidative stress in diabetes mellitus. J Diabetes Complicat. 2001;15(4):203-10.

16. Mozaffarian VA. Dictionary of Iranian Plant Names. Farhang Moaser, Tehran: 1996;271-2.

17. Coruh N, AG Sagdıcoglu Celep, Özgökçe F. Antioxidant properties of Prangos ferulacea (L.) Lindl., Chaerophyllum macropodum Boiss. and Heracleum persicum Desf. from Apiaceae family used as food in Eastern Anatolia and their inhibitory effects on glutathione-S-transferase. Food chem. 2007;100(3):1237-242.

18. Fortier AH. Current Protocols in Immunology. Newyork: 1996;1-5.

19. Hemati A, Azarnia M, Angaji AH. Medicinal effects of Heracleum persicum (Golpar). Middle-East J Sci Res. 2010;5(3):174-6.

20. Dalar A, Konczak I. Phenolic contents, antioxidant capacities and inhibitory activities against key metabolic syndrome relevant enzymes of herbal teas from Eastern Anatolia. Ind Crop Prod. 2013;44:383-90.

21. Mondal S, Ghosh D, Sagar N, Ganapaty S. Evaluation of Antioxidant, Toxicological and wound healing Properties of Hibiscus rosa-sinensis L.(Malvaceae) ethanolic leaves extract on different Experimental animal models. IJPER. 2016;50(4):620-37.

22. Veeraraghavan VP, Mohan SK, Jainu M, Gopan CS, Seshadri V. Ameliorating effects of Garcinia mangostana Linn pericarp extract on hepatic antioxidants in Diethyl nitrosamine (DEN) induced Hepatocellular Carcinoma (HCC). IJPER. 2015;49(4):344-52.

23. Giugliano D, Ceriello A, Paolisso G. Oxidative stress and diabetic vascular complications. Diabetes Care. 1996;19(3):257-7.

24. Tiedge M, Lortz S, Munday R, Lenzen S. Complementary action of antioxidant enzyme in the protection of bioengineered insulin-pr5oducing RIN m5f cells against the toxicity of reactive oxygen species. Diabetes. 1998;47(10):1578-85

25. Baynes JW. Role of oxidative stress in development of complications in diabetes. Diabetes. 1991;40(4):405-12.

26. Van Dam PS, Van Asbeck BS, Erkelens DW, Marx JJ, Gispen WH, Bravenboer B. The role of oxidative stress in neuropathy and other diabetic complications. Diabetes Metab Rev. 1995;11(3):181-92.

27. Nicolle E, Souard F, Faure P, Boumendjel A. Flavonoids as promising lead compounds in type 2 diabetes mellitus: molecules of interest and structure activity relationship. Curr Med Chem. 2011;18(17):2661-72.

28. Uyar A, Yener Z, Dogan A. Protective effects of Urtica dioica seed extract in aflatoxicosis: histopathological and biochemical findings. British Poultry Sci. 2016;57(2):235-45.

29. Yaman T, Yener Z, Celik I. Histopathological and biochemical investigations of protective role of honey in rats with experimental aflatoxicosis. BMC Compl Alter Med .2016;16(1):232.

30. Seven A, Güzel S, Seymen O, Civelek S, Bolayirli M, Uncul M. Effects of Vitamin E Supplementation on Oxidative Stress in Streptozotocin induced diabetic rats: investigation of liver and plasma. Yonsei Med J. 2004;45(4):703-10. 
31. Zhang C, Lu X, Tan Y, Li B, Miao X, Jin L, Cai L. Diabetes-induced hepatic pathogenic damage, inflammation, oxidative stress, and insulin resistance was exacerbated in zinc deficient mouse model. Plos One. 2012. DOI: 10.1371/journal.pone.0049257.

32. Noor A, Gunasekaran S, Manickam AS, Vijayalakshmi MA. Antidiabetic activity of Aloe vera and histology of organs in streptozotocin-induced diabetic rats. Current Sci. 2008;94(8):1070-6.

33. Ahmed D, Kumar V, Verma A, Gupta PS, Kumar H, Dhingra V, Sharma M. Antidiabetic, renal/hepatic/pancreas/cardiac protective and antioxidant potential of methanol/dichloromethane extract of Albizzia Lebbeck Benth. stem bark (ALEx) on streptozotocin induced diabetic rats. BMC Complem Altern M. 2014;14(1):243.

34. De Haan JB, Stefanovic N, Nikolic-Paterson D, Scurr LL, Croft KD, Mori TA, et al. Kidney expression of glutathione peroxidase- 1 is not protective against streptozotocin-induced diabetic nephropathy. Am J Physiol-Renal Physiol. 2005;289(3):544-F551.

35. Rousselot BD, Bastard JP, Jaudon MC, Delattre J. Consequences of the diabetic status on the oxidant/antioxidant balance. Diabetes and Metabolism. 2000;26(3): 163-76.

36. Darmaun D, Smith SD, Sweeten S, Sager BK, Welch S, Mauras N. Evidence for accelerated rates of glutathione utilization and glutathione depletion in adolescents with poorly controlled type 1 diabetes. Diabetes. 2005;54(1):190-6.

37. Yoshimura S, Komatsu N, Watanabe K. Purification and immunohistochemical localization of rat liver glutathione peroxidase. Biochem Biophsy Acta. 1980;621(1):130-7.

38. Asayama K, Yokota S, Dobashi K, Hayashibe H, Kawaoi A, Nakazawa S. Purification and immunoelectron microscopic localization of cellular glutathione peroxidase in rat hepatocytes: quantitative analysis by postembedding method. Histochemistry. 1994;102(3): 213-9.

39. Asayama K, Dobashi K, Kawada Y, Nakane T, Kawaoi A, Nakazawa S. Immunohistochemical localization and quantitative analysis of cellular glutathione peroxidase in foetal and neonatal rat tissues: fluorescence microscopy image analysis. Histochem J. 1996;28(1):63-71.
40. Deprem T, Gulmez N. Immunohistochemical localization of glutathione peroxidase 1 enzyme and its gene expression by RT-PCR in the liver tissue of healthy and diabetic mice. Turk J Vet Anim Sci. 2014;38(4):363-9.

41. Tascı SK, Gulmez N. Immunohistochemical distribution of glutathione peroxidase and its gene expression via RT-PCR in the liver tissue of melatonin-administered mice. Turk J Vet Anim Sci. 2014;38(2):145-50.

42. Deprem T, Yıldız SE, Sari EK, Bingol SA, Tasci SK, Aslan S, et al. Distribution of glutathione peroxidase 1 in liver tissues of healthy and diabetic rats treated with capsaisin. Biotech Histochem. 2105;90(1):1-7.

43. Muse KE, Oberley TD, Sempf JM, Oberley LW. Immunolocalization of antioxidant enzymes in adult hamster kidney. Histochem J. 1994;26(9):734-53.

44. Meral I, Yener Z, Kahraman T, Mert N. Effect of Nigella sativa on Glucose Concentration, Lipid Peroxidation, Anti-Oxidant Defence System and Liver Damage in Experimentally-Induced Diabetic Rabbits. J Vet Med A. 2001;48(10):593-9.

45. Kanter M, Coskun O, Korkmaz A, Oter S. Effects of Nigella sativa on oxidative stress and $\beta$-cell damage in streptozotocin-induced diabetic rats. Anat Rec $A$ Discov Mol Cell Evol Biol. 2004;279(1):685-91.

46. El-Kordy E A, Alshahrani AM. Effect of genistein, a natural soy isoflavone, on pancreatic $\beta$-cells of streptozotocin-induced diabetic rats: Histological and immunohistochemical study. JMAU. 2015;3(3):108-19.

47. Talchai C, Xuan S; Lin HV, Sussel L. Accili D. Pancreatic cell dedifferentiation as a mechanism of diabetic cell failure. Cell. 2012;150(6):1223-34.

48. Halban PA. 50 years forward: Beta cells. Diabetologia. 2015;58(8):1688-92.

49. Abunasef SK, Amin HA, Abdel-Hamid GA. A histological and immunohistochemical study of beta cells in streptozotocin diabetic rats treated with caffeine. Folia Histochem Cytobiol. 2014;52(1):42-50.

50. Osorio $\mathrm{PH}$, Castell-Rodríguez AE, Vargas-Mancilla J, Tovilla-Zárate CA, Ble-Castillo JL, Aguilar-Domínguez DE. Protective Action of Carica papaya on $\beta$-Cells in Streptozotocin-Induced Diabetic Rats. Int J Environ Res Public Health. 2016;3(5):446.

51. Alkan EE. The Investigation Of Therapeutic Effects Of Heracleum persicum And Bryonia Multiflora Plants On Experimentally Induced Diabetic Rats. PhD thesis. Yuzuncu Yil University, Van, Turkey. 2016.

\section{SUMMARY}

- STZ-induced degenerative changes in beta-cells caused decreases in the number of functioning beta-cells and insulin immunoreactivity in the pancreas of the diabetic rats.

- The pancreas of HP-treated rats were improved and the number of immunoreactive $\beta$ cells were significantly increased.

- Our data suggests that the STZ-induced immunohistochemical and histopathological alterations could be prevented by HP extract probably due to possess the ability to regenerate $\beta$-cells.

\section{ABOUT AUTHORS}

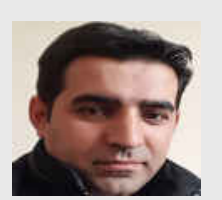

Dr. Turan YAMAN: Working as an assistant professor in the Department of Pathology, Faculty of Veterinary Medicine, Yuzuncu Yil University, Van, TURKEY. He has research experience in the field of Toxicopathology

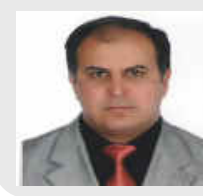

Dr. Ahmet UYAR: Working as an assistant professor in the Department of Pathology, Faculty of Veterinary Medicine, Yuzuncu Yil University, Van, TURKEY. He has research experience in the field of Toxicopathology.

Cite this article: Yaman T, Uyar A, Celik I, Alkan EE, Keles OF, Yener Z. Histopathological and Immunohistochemical Study of Antidiabetic Effects of Heracleum Persicum Extractln Experimentally Diabetic Rats. Indian J of Pharmaceutical Education and Research. 2017;51(3)Suppl:S450-57. 